\title{
Genetic basis for high population diversity in Protea-associated
}

\section{Knoxdaviesia}

\author{
Janneke Aylward $^{1 *}$, Emma T. Steenkamp $^{2}$, Léanne L. Dreyer ${ }^{1}$, Francois Roets ${ }^{3}$, \\ Michael J. Wingfield ${ }^{2} \&$ Brenda D. Wingfield ${ }^{4}$
}

\begin{abstract}
${ }^{1}$ Department of Botany and Zoology, Stellenbosch University, Private Bag X1, Matieland 7602, South Africa ${ }^{2}$ Department of Microbiology and Plant Pathology, University of Pretoria, Pretoria 0002, South Africa ${ }^{3}$ Department of Conservation Ecology and Entomology, Stellenbosch University, Private Bag X1, Matieland 7602, South Africa

${ }^{4}$ Department of Genetics, University of Pretoria, Pretoria 0002, South Africa
\end{abstract}

Authors' email addresses:

*Janneke Aylward, corresponding author (janneke@sun.ac.za)

Emma T. Steenkamp (emma.steenkamp@up.ac.za)

Léanne L. Dreyer (1d@ sun.ac.za)

Francois Roets (fr@sun.ac.za)

Michael J. Wingfield (mike.wingfield@up.ac.za)

Brenda D. Wingfield (brenda.wingfield@up.ac.za)

\section{Highlights}

- Heterothallism drives the diversity of Knoxdaviesia in the Cape Floristic Region.

- Their MAT1 idiomorphs comprise MAT1-1-1, MAT1-1-2, MAT1-2-1 and MAT1-2-7.

- The order of the MATl flanking genes conforms to the Sordariomycete consensus.

- The MAT1-2-7 gene was likely derived from MAT1-1-1 via recombination. 


\section{Abstract}

Sexual reproduction is necessary to generate genetic diversity and, in ascomycete fungi, this process is controlled by a mating type (MAT) locus with two complementary idiomorphs. Knoxdaviesia capensis and K. proteae (Sordariomycetes; Microascales;

Gondwanamycetaceae) are host-specific saprophytic fungi that show high population diversity within their Protea plant hosts in the Cape Floristic Region of South Africa. We hypothesise that this diversity is the result of outcrossing driven by a heterothallic mating system and sought to describe the MAT1 loci of both species. The available genome assembly of each isolate contained only one of the MAT1 idiomorphs necessary for sexual reproduction, implying that both species are heterothallic. Idiomorph segregation during meiosis, a 1:1 ratio of idiomorphs in natural populations and mating experiments also supported heterothallism as a sexual strategy. Long-range PCR and shot-gun sequencing to identify the opposite idiomorph in each species revealed no sequence similarity between MAT1-1 and MAT1-2 idiomorphs, but the homologous idiomorphs between the species were almost identical. The MAT1-1 idiomorph contained the characteristic MAT1-1-1 and MAT11-2 genes, whereas the MAT1-2 idiomorph consisted of the genes MAT1-2-7 and MAT1-2-1. This gene content was similar to that of the three species in the Ceratocystidaceae (Microascales) with characterized MAT loci. The Knoxdaviesia MAT1-2-7 protein contained and alpha domain and predicted intron, which suggests that this gene arose from MAT1-1-1 during a recombination event. In contrast to the Ceratocystidaceae species, Knoxdaviesia conformed to the ancestral Sordariomycete arrangement of flanking genes and is, therefore, a closer reflection of the structure of this locus in the Microascalean ancestor.

Keywords: Knoxdaviesia, MAT locus, mating, Microascales, Protea, reproduction 


\section{Introduction}

Sexual reproduction is universal across eukaryotic life, despite being more biologically costly than asexual propagation (Lehtonen et al., 2012; Ni et al., 2011; Otto, 2009; Stearns, 1987). Most fungi maintain both of these reproductive strategies that are controlled by diverse genetic mechanisms (Billiard et al., 2012; Ni et al., 2011). Evidence suggests that many fungi exploit the low cost of clonal reproduction during favourable environmental conditions, but switch to sexual reproduction under stress when adaptation becomes necessary (Ni et al., 2010; Nielsen and Heitman, 2007; Seymour et al., 2005). Novel allele combinations are essential for adaptation and the re-shuffling of genetic material enables selection against harmful or unfavourable genotypes that may be propagated through clonal reproduction (Lynch et al., 1993).

The mating type (MAT) genes of fungi control the recognition between sexual partners and the subsequent development of sexual progeny (Coppin et al., 1997; Perkins, 1987). In ascomycetes, mating type is determined by a single locus, MAT1, and two mating type idiomorphs (dissimilar alleles), MAT1-1 and MAT1-2 (Kronstad and Staben, 1997; Nelson, 1996; Turgeon and Yoder, 2000). Homothallic fungi have a MAT1-1/2 genotype (Turgeon and Yoder, 2000); both MATl idiomorphs occur in one genome, making them self-fertile. In heterothallic species, the absence of either idiomorph results in self-sterility that necessitates outcrossing between two individuals of opposite mating type for sexual reproduction (Kronstad and Staben, 1997; Nelson, 1996). Although it is widely accepted that the presence of both idiomorphs is necessary for sexual reproduction, fungal mating strategies are diverse and many exceptions to this rule have been observed (Heitman, 2015). For example, some species are self-fertile despite only possessing one MATl idiomorph (unisexual reproduction; Alby and Bennett, 2011; Glass and Smith, 1994; Lin et al., 2005; Wilson et al., 2015). 
The two idiomorphs of the ascomycete MATl locus each contain at least one open reading frame (ORF) with a characteristic motif (Turgeon and Yoder, 2000). The MAT1-1 idiomorph is defined by an ORF with an alpha domain (MAT1-1-1), although up to two additional "accessory" ORFs can occur in this idiomorph. The MAT1-2 idiomorph generally has a single ORF (MAT1-2-1) with an HMG-box motif. The functions of each of these MAT1 genes is not fully understood, but it is believed that each idiomorph encodes transcription factors (Herskowitz, 1989) that ultimately perform a dual function. Firstly, the transcription factors mediate a hormonal recognition mechanism between individuals by producing a pheromone and receptors for the pheromone of the opposite mating type (Coppin et al., 1997; Glass et al., 1990; Ni et al., 2011). Secondly, these genes are involved in the formation of sexual structures (Coppin et al., 1997). Molecular studies have shown that the MAT1-1-1 gene alone is able to induce fertilization, but in Podospora anserina, the accessory genes analogous to MAT1-1-2 and MAT1-1-3 are needed for the sexual structures to develop fully (Debuchy et al., 1993), supporting the dual function. As the only consistently occurring ORF on the MAT1-2 idiomorph, MAT1-2-1 appears to be involved in ascomatal development and is the sole determinant of the necessary functions in this mating type (Coppin et al., 1997; Staben and Yanofsky, 1990).

Of the five Microascales (Sordariomycetes) families (Maharachchikumbura et al., 2015; Réblová et al., 2011) only three species in the predominantly plant-associated, agriculturally important Ceratocystidaceae (De Beer et al., 2014) have been studied extensively in terms of mating type genetics. The sweet potato pathogen, Ceratocystis fimbriata s.s., is homothallic and undergoes unidirectional mating type switching whereby it loses its MAT1-2-1 gene and becomes self-sterile (Harrington and McNew, 1997; Wilken et al., 2014). The other two Ceratocystidaceae species studied are members of the genus Huntiella that typically show a saprophytic association with tree wounds (Van Wyk et al., 2006). Both of the studied species 
in this genus are heterothallic (Wilson et al., 2015), although H. moniliformis is also capable of unisexual reproduction; since it contains a single MAT1 idiomorph, yet produces ascomata (Wilson et al., 2015). One trait that unites the diverse mating strategies in Ceratocystidaceae is their deviation from the consensus gene order of the Sordariomycetes. The cytoskeleton assembly control (SLA2) and DNA lyase (APN2) genes that flank the MAT locus in almost all Sordariomycetes (Debuchy and Turgeon, 2006) have an altered order and orientation in the Ceratocystidaceae. The genes that typically flank the downstream region of MAT1 loci have shifted to an upstream position in C. fimbriata. A similar shift is evident in the two studied Huntiella species, although the APN2 gene has shifted to a genomic position far from the MAT1 locus (Wilson et al., 2015).

The aim of this study was to describe the MAT1 locus of two saprophytic, but host-specific species in the Gondwanamycetaceae, which is also a member of the Microascales (Réblová et al., 2011). These fungi (Knoxdaviesia capensis and K. proteae) occur in the seed cones of Protea, a keystone plant genus in the Cape Floristic Region of South Africa (Bergh et al., 2014; Cowling, 1992; Manning and Goldblatt, 2012). The arthropod, and possibly bird, vectors of these fungi disperse ascospores between Protea flower heads (Roets et al., 2011b). After flowering, the Protea inflorescence matures into an enclosed seed cone in which $K$. capensis and $K$. proteae are visible on decaying floral structures as ascomata that present spore droplets on long ostiolar necks (Wingfield and Van Wyk, 1993; Wingfield et al., 1988). Although conidiophores may also be present, $K$. capensis and $K$. proteae sexual structures are abundant within infructescences (Wingfield and Van Wyk, 1993; Wingfield et al., 1988), indicating that sexual reproduction is prevalent and likely the dominant mode of reproduction at this stage of their life-cycle. As ascomycete fungi, $K$. capensis and $K$. proteae are haploid during the vegetative state and sexual reproduction would thus only add genetic diversity if it is not a result of self-fertilization (Fincham and Day, 1963; Milgroom, 1996; Moore and 
Novak Frazer, 2002). High gene and genotypic diversity and random allele association within two populations of $K$. proteae (Aylward et al., 2014, 2015b) and nine populations of $K$. capensis (Aylward, unpublished) strongly suggest that sexual reproduction in these species is non-selfing. Protea-associated Knoxdaviesia individuals, therefore, regularly recombine to produce genetically novel offspring, but whether outcrossing is a prerequisite for sexual reproduction in these species (i.e. heterothallism) or whether it is optional (i.e. homothallism) remains unknown.

The genomes of $K$. capensis and $K$. proteae have recently been sequenced (Aylward et al., 2016). In this study, we used these genomes to investigate the genetic basis of mating in Knoxdaviesia. In so doing, we tested the hypothesis that the genetic diversity observed in natural populations of these species is due to outcrossing driven by a heterothallic mating system. As a secondary aim, we compared the identified Knoxdaviesia MAT1 loci to the three species in the Ceratocystidaceae with characterized MAT1 loci.

\section{Materials and methods}

\subsection{Fungal isolates and genome sequences used}

The genomes of $K$. capensis CBS139037 (LNGK00000000.1) and K. proteae CBS140089 (LNGL00000000.1) were sequenced in a previous study (Aylward et al., 2016) and are available in GenBank ${ }^{\circledR}$ (Benson et al., 2013). The MAT1 locus of C. fimbriata CMW14799, previously characterized from its sequenced genome (Wilken et al., 2014), was also obtained from GenBank (KF033902.1; KF033903.1). Other than the Knoxdaviesia genome isolates, three additional strains of $K$. capensis (CMW40886, CMW40889, CMW40892) and $K$. proteae (CMW40879, CMW40882, CMW40883) were used in this study to perform crossing experiments. All isolates were routinely cultured on Potato Dextrose Agar (PDA; Merck, Wadeville, South Africa) for approximately seven days at $25^{\circ} \mathrm{C}$ and maintained at $4{ }^{\circ} \mathrm{C}$. 


\subsection{Identification of MAT loci from genome sequences}

Ceratocystis fimbriata s.s. is currently the species most closely related to Knoxdaviesia that has a characterized MAT1 locus with available gene models. The predicted proteins of the MAT1 locus of C. fimbriata CMW14799 (AHV84683-84701) were used to search for the MAT1 locus in the genomes of $K$. capensis and $K$. proteae by performing local BLASTx searches in CLC Genomics workbench 6 (CLC Bio, Denmark). Preliminary analyses identified a single MAT1 idiomorph from each Knoxdaviesia genome and revealed that the two genomes contained opposite MAT1 idiomorphs. Subsequently, we mapped the raw sequence reads from the K. capensis genome (GenBank Accession: SRX1453186, SRX1453795 and SRX1453796) to the K. proteae MAT1 region in CLC Genomics workbench to identify the terminal ends of the MAT1 locus in $K$. proteae. The procedure was repeated using the $K$. proteae raw sequence reads (GenBank Accession: SRX1453891, SRX1453905 and SRX1453906) and the K. capensis MAT1 region.

\subsection{Identification of the opposite MAT idiomorph in each species}

Since each Knoxdaviesia genome contained a single MAT1 idiomorph, the opposite idiomorph of each species had to be determined from a strain with the opposite mating type. Primers were designed in the conserved flanking regions of the MAT1 locus in both Knoxdaviesia genomes (Table 1; Fig. 1) and used, in conjunction with internal primers (Table 1; Fig. 1), to amplify the opposite idiomorph in K. capensis CMW40886 and K. proteae CMW40882. The $50 \mu \mathrm{l}$ reactions contained $1.75 \mathrm{mM} \mathrm{MgCl}_{2}, 0.3 \mathrm{mM}$ of each dNTP, $0.5 \mu \mathrm{M}$ of each primer, approximately $250 \mathrm{ng}$ template DNA, $2 \mu \mathrm{DMSO}, 10 \mu 1$ 5x KAPA LongRange Buffer and 1.25 units of KAPA LongRange HotStart DNA Polymerase (KAPA Biosystems, Inc., Wilmington, MA). Initial denaturation was performed at $94^{\circ} \mathrm{C}$ for 4 minutes, followed by 35 cycles of $94^{\circ} \mathrm{C}$ for 30 seconds, $55.5^{\circ} \mathrm{C}$ for 30 seconds and $68^{\circ} \mathrm{C}$ for 
Table 1

Summary of the Knoxdaviesia MAT1 primers used in this study

Primers

\begin{tabular}{|c|c|c|c|c|}
\hline Number & Name & $5^{\prime}-3^{\prime}$ & Alpha domain & $\begin{array}{l}\text { Product } \\
\text { size (bp) }\end{array}$ \\
\hline $1 \mathrm{a}$ & $\mathrm{KcM} 1-\mathrm{F}$ & CCG CAC TGT ACA TCA CAA CA & $1 \mathrm{a} \leftrightarrow 2$ & 835 \\
\hline $1 b$ & KpM1-F & CCT CGT CTC GAA TGA AGG AG & $1 \mathrm{~b} \leftrightarrow 2$ & 357 \\
\hline 2 & KcM1-R & GGT CAC CGA AAA GAA GAC CA & HMG-box domain & \\
\hline 3 & KpHMG-F & ATC CTC ATG CCA CAA TAC CC & $3 \leftrightarrow 4$ & 516 \\
\hline 4 & KpHMG-R & GAA GTT GAA GTC CGC TTT GC & Long range MAT1-1 & \\
\hline 5 & KxMAT-F & TGG TTG AAA GGG AAA TGA GG & $5 \leftrightarrow 2$ & 3914 \\
\hline $6 a$ & KxMAT-R & AAG ACA AAG GAC GGC CTA GC & $1 \mathrm{c} \leftrightarrow 6 \mathrm{a}$ & 6268 \\
\hline $1 \mathrm{c}$ & LR-KpM1F & GAG TGG CCT TGT CTT GAC CT & Long range MAT1-2 & \\
\hline \multirow[t]{2}{*}{$6 \mathrm{~b}$} & Apn-R & ATC TGT GCC GGT ACT TCA ACC & $5 \leftrightarrow 4$ & 5751 \\
\hline & & & $3 \leftrightarrow 6 b$ & 2825 \\
\hline
\end{tabular}




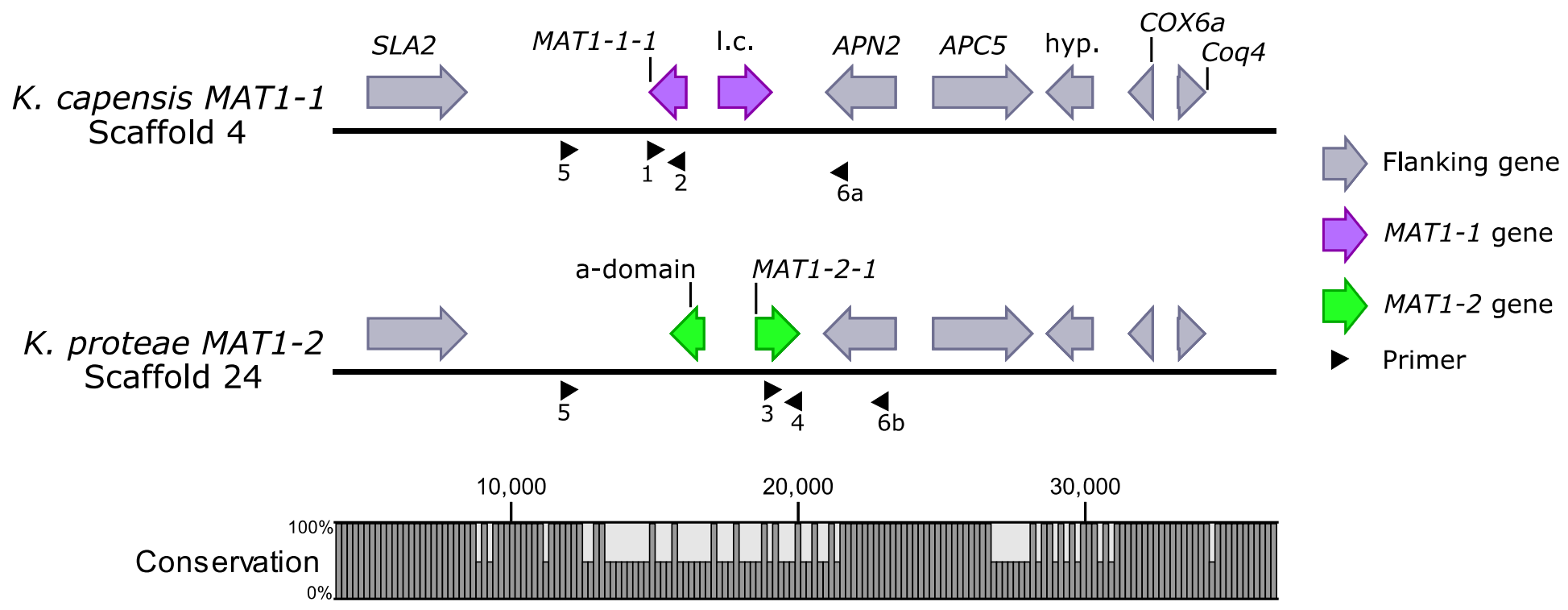

Figure 1. The MAT1 mating type locus identified from the genomes of Knoxdaviesia capensis and K. proteae. The graph indicates nucleotide sequence conservation between the loci of the two fungi. Open reading frames are indicated by blocked arrows. The lack of conservation in the APC5 gene is due to missing sequence data in the $K$. proteae genome sequence. $1 . c .=$ low complexity region protein, hyp. $=$ hypothetical protein, a-domain $=$ alpha domain-containing protein. See Table 1 for primer names and sequences. Primers $1 \mathrm{a}, 1 \mathrm{~b}$ and $1 \mathrm{c}$ lie in the same approximate location. 
one minute per $\mathrm{kb}$ to be amplified (Table 1). The final extension step was at $72^{\circ} \mathrm{C}$ for 10 minutes. The products were submitted for paired-end shotgun sequencing on the Illumina MiSeq platform at Inqaba Biotechnical Industries (Pty) Ltd., Pretoria, South Africa.

The next generation reads were trimmed with Trimmomatic (Bolger et al., 2014), discarding the first 10 bases, those with an average phred score below 25 (using a sliding window of four base pairs), and reads < $30 \mathrm{bp}$ in length. The quality of the sequences was confirmed with FastQC 0.11.4 (Babraham Bioinformatics, Babraham Institute, Cambridge). A de novo assembly of the trimmed sequences of each idiomorph was performed in CLC Genomics workbench. Subsequently, the sequence reads were mapped back onto the assembly of each idiomorph to detect potential errors. In order to compare the two idiomorphs in each species and the two pairs of homologous idiomorphs, dotplot comparisons of the nucleic acid sequences were computed with YASS (Noé and Kucherov, 2005) using the default parameters. Since repeat structures have been found in the MAT1 locus of $C$. fimbriata (Wilken et al., 2014), the Knoxdaviesia MAT1 loci were interrogated for repeat clusters with RepFind (Betley et al., 2002).

\subsection{Knoxdaviesia MAT genes}

WEBAUGUSTUS (Hoff and Stanke, 2013) was used to predict open reading frames (ORFs) in the MAT1 loci obtained from the Knoxdaviesia genomes and the amplified idiomorphs, using gene models from the closest available relative, Fusarium graminearum. The putative identities of the predicted ORFs were determined by DELTA-BLAST protein searches (Boratyn et al., 2012) at the National Centre for Biotechnology Information (NCBI; http://blast.ncbi.nlm.nih.gov/Blast.cgi). Conserved domains in putative MAT1 proteins were identified with searches at Interpro (Mitchell et al., 2015) and NCBI's Conserved Domains Database (CDD; Marchler-Bauer et al., 2015). 
The Knoxdaviesia MAT1 proteins were compared with those of $C$. fimbriata (KF033902), $H$. moniliformis and H. omanensis (obtained from A. Wilson). In addition, we used the MAT1-11, MAT1-1-2 and MAT1-2-1 proteins of six other Sordariomycetes also used by Wilken et al. (2014): Cryphonectria parasitica (AF380365/AF380364), Cordyceps takaomontana (AB096216/AB084921), Fusarium fujikuroi (AF100925/AF100926), Magnaporthe grisea (AB080670/AB080671), Neurospora crassa (M33876/ M54787) and Podospora anserina (X73830/X64194/X64195). These were aligned to the Knoxdaviesia proteins and to the consensus sequences of the alpha (PFAM04769) and HMG-box (PFAM00505) domains, using the accurate alignment algorithm in CLC Genomics workbench. The consensus sequences were obtained from the protein families (Pfam) database (Finn et al., 2014).

\subsection{Distribution of MAT idiomorphs in natural populations and ascomata}

To determine the abundance of each MAT1 idiomorph in natural populations, DNA previously extracted from 94 strains of $K$. capensis isolated from six different hosts (Aylward et al., 2015a; Aylward, unpublished) and 184 strains of $K$. proteae from a single host (Aylward et al., 2014, 2015b) in the Cape Floristic Region, were used (Table 2). Primers KcM1-F (1a in Fig. 1) and KcM1-R (2 in Fig. 1), that flank the conserved alpha domain of MAT1-1-1, and KpHMG-F (3 in Fig. 1) and KpHMG-R (4 in Fig. 1), that flank the HMG-box of MAT1-2-1 in the two Knoxdaviesia species were designed with Primer3 (Table 1;

Untergasser et al., 2007). A new forward primer, Kp-M1-F (1b in Fig. 1), was later designed to bind to the $K$. proteae alpha domain region with greater specificity (Table 1 ). The sizes of the amplicons for these two conserved regions were calculated to differ by at least $150 \mathrm{bp}$, in order to be distinguished on an agarose gel and, therefore, to identify the MAT1 idiomorph using a single multiplex PCR. The $20 \mu \mathrm{l}$ PCRs contained $10 \mu \mathrm{l}$ KAPA Taq ReadyMix (Kapa Biosystems, Inc., Boston, USA), $\mathrm{MgCl}_{2}$ at a final concentration of $2.75 \mathrm{mM}, 0.4 \mu \mathrm{M}$ each of 


\section{Table 2}

Knoxdaviesia strains and populations used in this study

\begin{tabular}{|c|c|c|c|c|}
\hline Species & Host & Location $^{A}$ & $\begin{array}{l}\text { Number } \\
\text { of strains }\end{array}$ & Reference \\
\hline $\begin{array}{l}\text { Knoxdaviesia capensis } \\
\text { CMW40890 }\end{array}$ & $\begin{array}{l}\text { Protea longifolia } \\
\text { Andrews }\end{array}$ & Hermanus & 1 & Aylward et al. (2016) \\
\hline$"$ & P. coronata Lam. & Ataraxia & 15 & Aylward (unpublished) \\
\hline " & $"$ & Du Toits Kloof & 11 & $"$ \\
\hline$"$ & $"$ & Greyton & 9 & $"$ \\
\hline " & $"$ & Kleinmond & 5 & $"$ \\
\hline$"$ & $"$ & Helderberg & 9 & $"$ \\
\hline$"$ & P. neriifolia $\mathrm{R}$. Br. & Betty's Bay & 6 & $"$ \\
\hline " & $"$ & Kogelberg & 8 & $"$ \\
\hline " & P. lepidocarpodendron $\mathrm{L}$. & Betty's Bay & 7 & $"$ \\
\hline$"$ & P. longifolia & Kogelberg & 9 & $"$ \\
\hline \multirow{4}{*}{$\begin{array}{l}\text { Knoxdaviesia proteae } \\
\text { CMW } 40880\end{array}$} & $\begin{array}{l}\text { P. repens } \mathrm{L} \text {. } \\
\text { " }\end{array}$ & $\begin{array}{l}\text { Gouritz } \\
\text { Franschoek }\end{array}$ & $\begin{array}{l}7 \\
10\end{array}$ & $\begin{array}{l}\text { Aylward et al. (2015b) } \\
"\end{array}$ \\
\hline & P. repens & Stellenbosch & 1 & Aylward et al. (2016) \\
\hline & $"$ & Gouritz & 83 & Aylward et al. (2014) \\
\hline & $"$ & Franschoek & 101 & Aylward et al. (2015a) \\
\hline
\end{tabular}

${ }^{a}$ All localities are in the Western Cape Province, South Africa 
the alpha domain and HMG-box primer pairs and approximately $150 \mathrm{ng}$ template DNA. PCR cycling conditions were $95^{\circ} \mathrm{C}$ for 3 minutes, followed by 35 cycles of $94^{\circ} \mathrm{C}$ for 30 seconds, $55^{\circ} \mathrm{C}$ for 30 seconds and $72^{\circ} \mathrm{C}$ for 1.15 minutes, and a final extension step of $72^{\circ} \mathrm{C}$ for 10 minutes. The hypothesis of a 1:1 distribution of MAT1-1 and MAT1-2 idiomorphs within different sampling localities and from different host species was tested with Pearson's ChiSquare and two-sided binomial tests in R version 3.2.3 (R Core Team, 2014).

The distribution of MAT1 idiomorphs in ascospores derived from a single parent was also investigated. For both $K$. capensis and $K$. proteae, single ascospore progeny were cultured from a spore droplet taken from a single ascoma following the protocol of Wilson et al. (2015). Since Knoxdaviesia species do not readily from sexual structures in culture, a spore droplet from an ascoma on P. coronata (for K. capensis) and P. repens (for K. proteae) flowers were transferred to $20 \mu \mathrm{l}$ Soltrol 130 oil (Chemfit, Gauteng, South Africa), vortexed and streaked out onto half-strength PDA (19.5g PDA/L; Merck, Wadeville, South Africa). For $K$. proteae, ascospores germinated only if an equal volume (20 $\mu 1)$ of sterile water was mixed with the Soltrol oil prior to streaking. Plates were incubated at $25^{\circ} \mathrm{C}$ and 30 germinating ascospores from each species were transferred onto fresh half-strength PDA after approximately 48 hours. After approximately 10 days at $25^{\circ} \mathrm{C}$, DNA from the single ascospore progeny was extracted and amplified with the Extract-N-Amp ${ }^{\mathrm{TM}}$ Plant PCR Kit (Sigma-Aldrich, Steinham, Germany) according to the manufacturer's instructions. PCR reaction conditions and protocols followed those described above. The hypothesis of a 1:1 distribution of MAT1-1 and MAT1-2 idiomorphs within the spore drops of each species was again tested with Pearson's Chi-Square and two-sided binomial tests in R. 


\subsection{Knoxdaviesia mating type experiments}

Knoxdaviesia species rarely produce sexual reproductive structures in culture and then only when an ascospore mass is cultured directly from the host (Wingfield and Van Wyk, 1993; Wingfield et al., 1988). Subsequent propagation in culture is exclusively asexual. We attempted to induce the formation of ascomata in culture by reciprocally pairing two MATI-1 and two MAT1-2 strains from each species in all six possible combinations on half-strength PDA. The pairings, therefore, included four MAT1-1 vs. MAT1-2 crossings and two negative controls (MAT1-1 vs. MAT1-1 and MAT1-2 vs. MAT1-2). All six pairings were made in triplicate by (1) sub-culturing two strains approximately two cm apart (Wilson et al., 2015), (2) streaking two conidial suspensions on opposite sides of plates (Gilgado et al., 2010) and (3) combining equal volumes of two conidial suspensions and streaking the mixture. We also paired $K$. capensis and $K$. proteae to observe whether recognition and subsequent ascomatal development would take place. Plates were incubated at room temperature and in the dark to simulate the infructescence environment. They were monitored for up to four months for the presence of ascomata.

\section{Results}

\subsection{Identification of the MAT1 locus}

The BLASTx searches conducted on the K. capensis and K. proteae genomes highlighted regions of $K$. capensis scaffold 4 as comprising sequences with homology to MAT1-1-1 and common MATl flanking regions. BLAST searches could not detect the commonly occurring MAT1-1-2 gene at this locus or in the rest of the genome. Scaffold 24, 30 and 37 of $K$. proteae contained ORFs with an HMG-box domain, but only the predicted protein in scaffold 
24 had homology to fungal MAT1-2-1 proteins (Table S1): Ustilaginoidea virens (KDB17701), Metarhizium brunneum (KID72395) and Metarhizium majus (KID83388). Mapping the raw sequence reads of the $K$. capensis MAT1-1 genome against the $K$. proteae MAT1-2 genome, and vice versa (Fig. S1) illustrated that the MAT1-1 idiomorph (7744 bp) is slightly larger than the MAT1-2 idiomorph (4968 bp).

The opposite MAT idiomorph for each Knoxdaviesia species was amplified in two parts using the primers designed from the conserved MAT1 flanking regions in the Knoxdaviesia genomes and internal primers designed from the MAT1 loci. These overlapping sequences were pooled before constructing Illumina paired-end libraries for each idiomorph. The MAT1-1 locus of $K$. proteae was amplified with KxMAT-F (5) and KcM1-R (2), and LRKpM1F (1c) and KxMAT-R (6a), respectively yielding amplicons of approximately $3.9 \mathrm{~kb}$ and $6.3 \mathrm{~kb}$. The $K$. capensis MAT1-2 locus was amplified with KxMAT-F (5) and KpHMG-R (4), and KpHMG-F (3) and Apn-R (6b), yielding 5.8 and $2.8 \mathrm{~kb}$ amplicons, respectively. The MAT1-1 idiomorph of $K$. proteae could be assembled into a 9374 bp contig and the MAT1-2 idiomorph of K. capensis into a 6908 bp contig. For K. capensis and K. proteae, respectively, $93.8 \%$ and $95.1 \%$ of the trimmed sequence reads mapped back to the assembly. Both of these assemblies were larger than the estimated size of each idiomorph, reflecting the upstream and downstream flanking regions that were included in the long-range PCR. The idiomorph sizes were again estimated by mapping the genome reads of the opposite mating type to each idiomorph. The $K$. proteae MAT1-1 idiomorph was estimated at 7795 bp and the K. capensis MAT1-2 idiomorph at 4988 bp. 


\subsection{Knoxdaviesia MAT1 genes}

\subsubsection{MAT1-1 idiomorph}

WEBAUGUSTUS predicted two ORFs in each MAT1 idiomorph. In the $K$. capensis genome, a conserved motif search identified an alpha-box (PS51325)/MAT alpha 1 domain (IPR006856; PFAM04769) at amino acid residues 57-196 in the first MAT ORF (Kc1_g2). The second MAT ORF (Kc1_g3) contains a low complexity region and could not be matched to any protein on the NCBI protein database. After masking the low complexity region, a BLASTp search revealed poor similarity to the MAT1-1-2 gene of Cordyceps militaris. Similar results were obtained for the two ORFs predicted from the K. proteae MAT1-1 locus. Detailed BLAST results are given in supplementary Table S1.

The predicted MAT1-1-1 genes of both Knoxdaviesia species contained a single intron occurring within the conserved alpha domain (Fig. 2A). The position of this intron in the conserved protein domain was identical to the position of the intron in the MAT1-1-1 proteins of other Sordariomycetes (Debuchy and Turgeon, 2006), including $C$. fimbriata and $H$. omanensis (Wilken et al., 2014; Wilson et al., 2015). This domain was well conserved between Knoxdaviesia and the Ceratocystidaceae species, although $C$. fimbriata displays several deviations from amino acids that remain conserved in Knoxdaviesia and Huntiella (Fig. 2A).

Alignment of the Knoxdaviesia low complexity-region proteins to the Ceratocystidaceae (Fig. 2B) and other Sordariomycete MAT1-1-2 proteins (Fig. S2) showed that they contain the conserved HPG (Histidine-Proline-Glycine) domain (PFAM17043) that has been proposed for this protein by Debuchy and Turgeon (2006). In the Ceratocystidaceae this motif is, however, HYG (Histidine-Tyrosine-Glycine; Wilken et al., 2014). Kanematsu et al. (2007) proposed a conserved PPF (Proline-Proline-Phenylalanine) motif, but in Knoxdaviesia only 


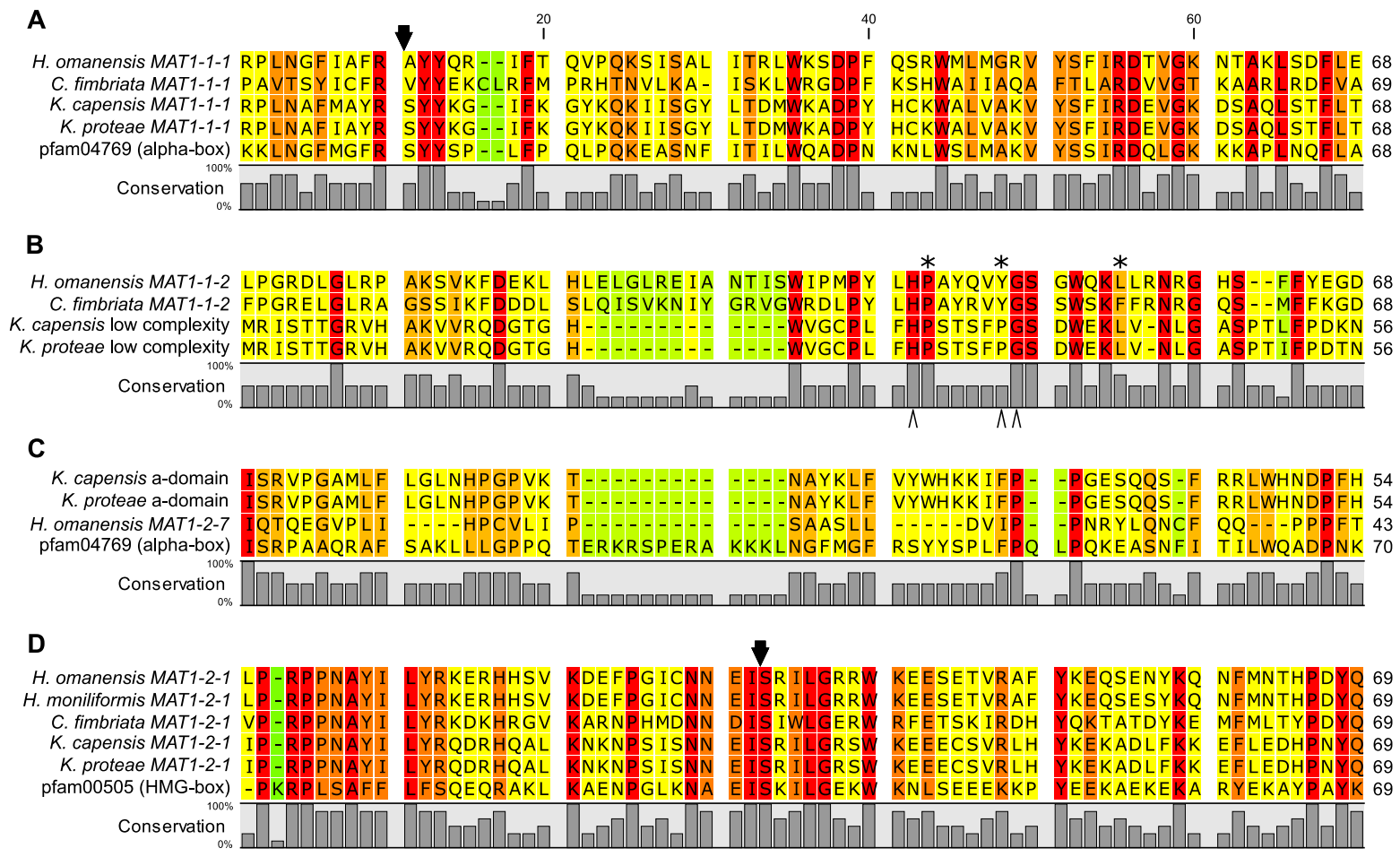

Figure 2. Alignment of conserved regions of the MAT1 locus of Knoxdaviesia, Huntiella and Ceratocystis fimbriata. A) Alpha domain of MAT1-1-1, B) proposed PPF $\left({ }^{*}\right)$ and HPG $\left({ }^{\wedge}\right)$ domains of MAT1-1-2, C) similarity between Knoxdaviesia alpha domain-containing proteins and Huntiella MAT1-2-7 and D) HMG-box domain of MAT1-2-1. The conservation of residues is illustrated with a spectrum from green to red, with green representing $<30 \%$, yellow $<65 \%$, orange $<100 \%$ and red $100 \%$ amino acid identity. Conserved intron positions are indicated with a black arrow. 


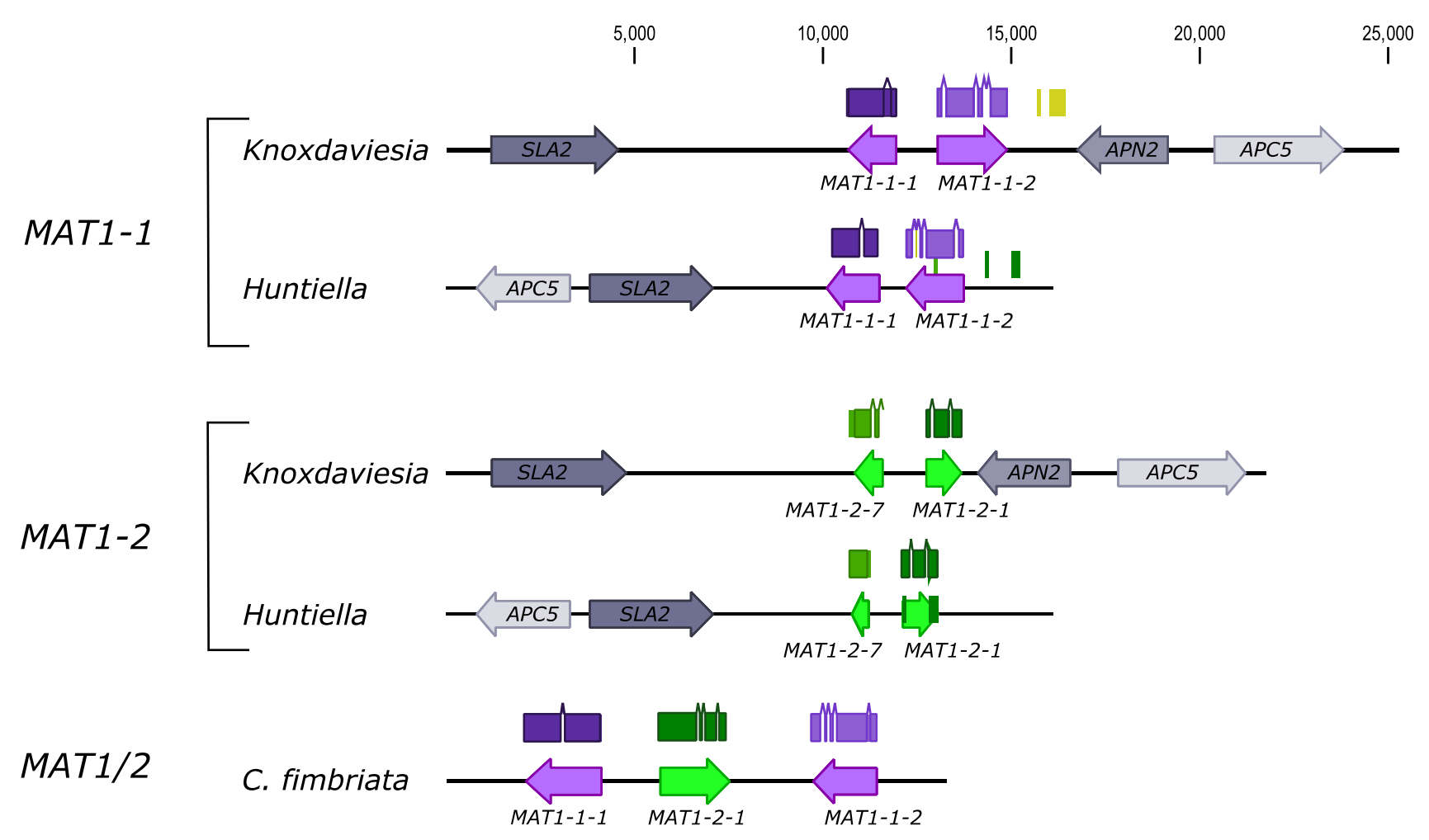

Figure 3. Comparison between the MAT1 locus organisation of Knoxdaviesia, Huntiella and Ceratocystis fimbriata. Gene models are indicated above the MAT1 genes as boxes (exons) and gaps (introns). APN2 is not present in the regions flanking MAT1 of Huntiella. 
the two Prolines were present, whereas only the first Proline is conserved in the Ceratocystidaceae species. The gene models predicted for these low complexity-region proteins also agree with the MAT1-1-2 gene model of $C$. fimbriata (Fig. 3), providing additional evidence that they represent the MAT1-1-2 gene in Knoxdaviesia. These proteins were longer (548 in K. capensis and 547 in K. proteae) than any of the other MAT1-1-2 proteins considered here, partly owing to the low complexity region of approximately 24 amino acids at the C-terminal ends.

\subsubsection{MAT1-2 idiomorph}

The first MAT ORF (Kp2_g2) in the genome of $K$. proteae is an ORF smaller than the putative Knoxdaviesia MAT1-1-1 genes, but with homology to the MAT alpha 1 domain. The second $K$. proteae ORF (Kp2_g3) contained a HMG-box domain (IPR009071; PFAM00505) at residues 156-230, analogous to MAT1-2-1 proteins. As with the K. proteae MAT1-1 idiomorph, the ORFs predicted from the assembled K. capensis MAT1-2 idiomorph were also identified as an alpha domain-containing protein and the MAT1-2-1 gene (Table S1).

Whereas the Knoxdaviesia MAT1-2-1 proteins showed a high level of conservation with known MAT1-2-1 proteins (Figs. 2d, S2), including a conserved intron position (Debuchy and Turgeon, 2006), the first ORF in the Knoxdaviesia MAT1-2 idiomorphs was unusual. These alpha domain-containing proteins were almost half the size of the Knoxdaviesia MAT1-1-1 proteins (208 vs. 401 amino acids) and alignment indicated that the conserved domain is the only common region (Fig. S3). The conserved domain in these proteins also showed more deviation from the consensus MAT alpha 1 domain than MAT1-1-1 proteins. Surprisingly, however, the alpha domain proteins had a predicted intron at the same position as the MAT11-1 proteins (Fig. S3), suggesting that the two have a common origin. 
Wilson et al. (2015) recently described a new MAT1 gene from the MAT1-2 idiomorph of $H$. omanensis. This gene, named MAT1-2-7, lies upstream of MAT1-2-1 and does not have a known conserved domain, neither does it contain an intron. Alignment between the Knoxdaviesia alpha domain-containing proteins, the H. omanensis MAT1-2-7 protein and the consensus MAT alpha 1 domain (Fig. 2C) showed that the Knoxdaviesia and Huntiella proteins are similar. This suggests that the Huntiella MAT1-2-7 protein may also have arisen from an alpha domain-containing protein. We thus propose that these genes are homologous and therefore consider the Knoxdaviesia MAT1-2 alpha domain-containing genes as MAT1-27.

\subsubsection{Genes flanking the MAT locus}

BLAST searches identified the ORFs flanking the MAT1 locus in both Knoxdaviesia species as the SLA2 and APN2 genes (Fig 1; Table S1). Other genes are commonly associated with the MAT locus (e.g. the cytochrome $\mathrm{C}$ oxidase VIa subunit (COX6a), anaphase promoting complex subunit 5 (APC5) and coenzymeQ biosynthesis (Coq4) genes) and were also detected downstream of APN2. Unlike the Ceratocystidaceae, the Knoxdaviesia MAT1 locus conformed to the ancestral Sordariomycete arrangement of flanking genes (Fig 3; Debuchy and Turgeon, 2006).

\subsection{Knoxdaviesia capensis and K. proteae MAT1 comparison}

Dotplot comparisons between the opposite $M A T$ idiomorphs in each of the species indicated that the two idiomorphs share little sequence similarity, with the only exception being two similar 160 bp fragments in the $K$. proteae idiomorphs (Fig. 4A, B). The size difference between the MAT1-1 and MAT1-2 idiomorphs can be ascribed to smaller ORFs in the MAT12 idiomorph and a smaller intergenic region (386 bp in MAT1-1 vs. >1.8 kb in MAT1-2) separating the MAT1-2-1 and APN2 genes. In contrast, the homologous MAT1-1 and MAT1-2 

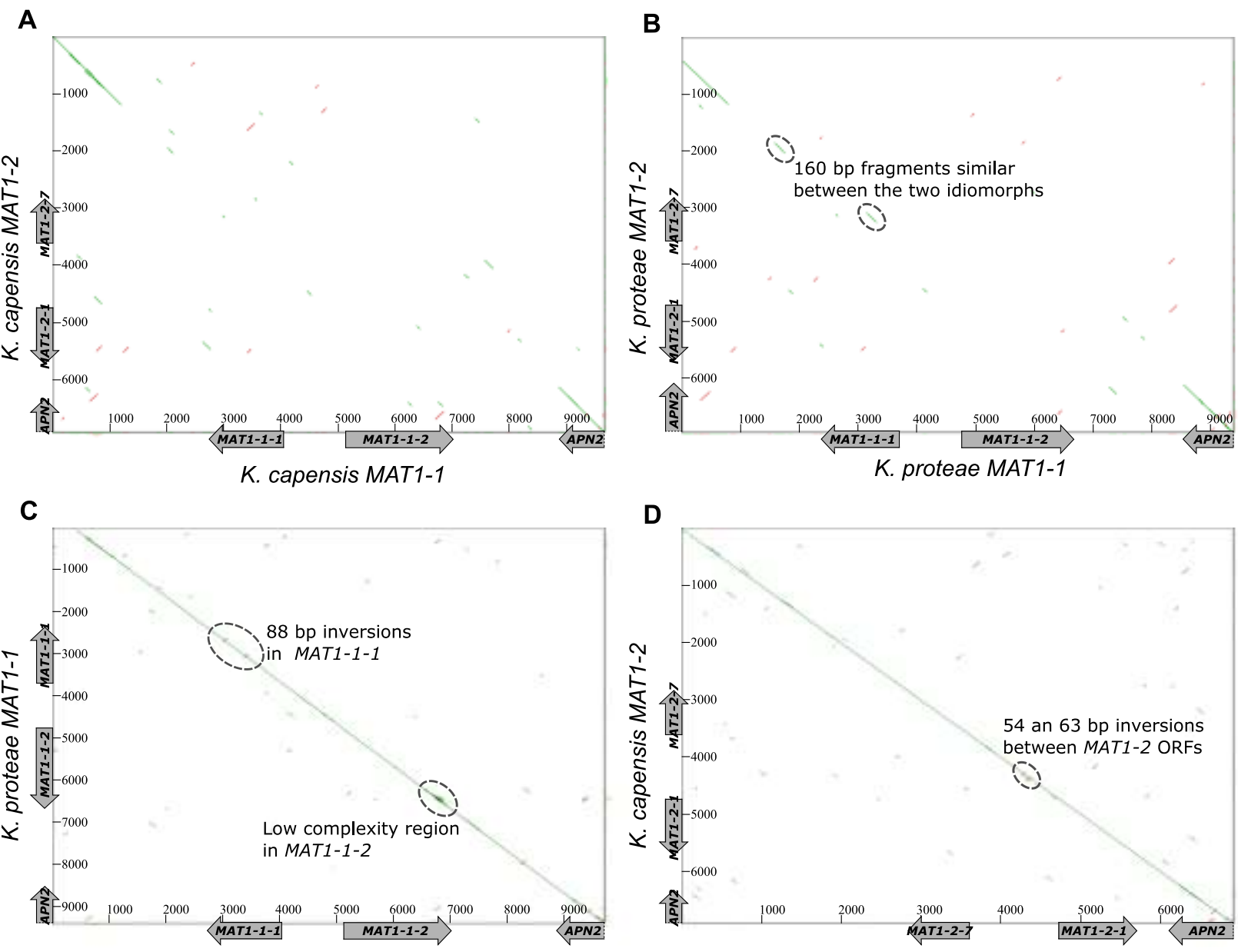

D

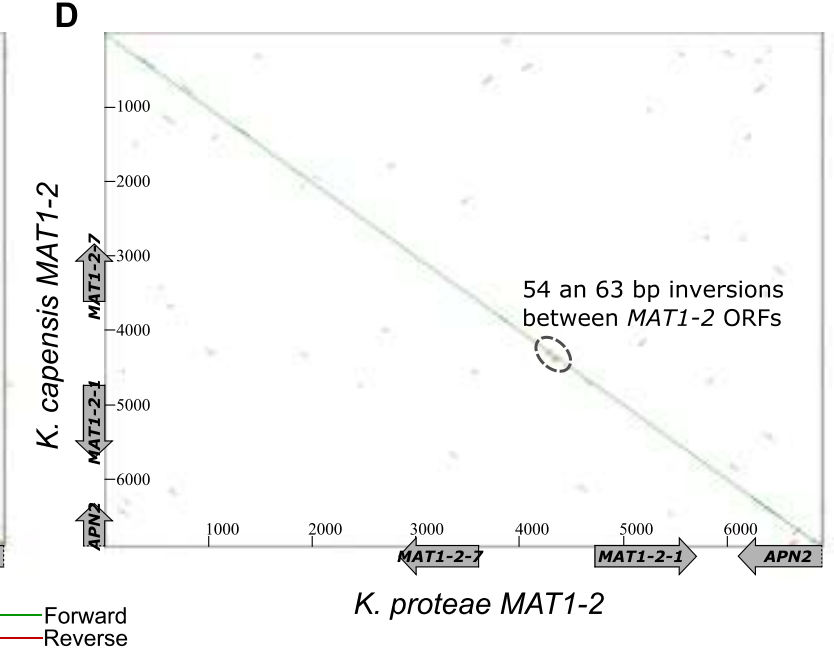

Figure 4. Pairwise dotplot comparisons between the MATl idiomorphs of Knoxdaviesia capensis and K. proteae. Intra-specific comparisons between the A) K. capensis and B) $K$. proteae idiomorphs, as well as inter-specific comparisons between the homologous $\mathrm{C}$ ) MAT1-1 and D) MAT1-2 idiomorphs are shown. The positions of the MAT1-1, MAT1-2 and APN2 genes are indicated on each plot. 
idiomorphs shared $84.3 \%$ and $86.4 \%$ sequence identity at the nucleotide level. The dotplot indicated two small inversions between each of the idiomorphs in $K$. capensis and K. proteae and illustrated the low complexity region of the MAT1-2-7 gene (Fig. 4C, D). Significant repeats, as are present in the unswitched $C$. fimbriata MAT1 locus (Wilken et al., 2014), could not be identified in the Knoxdaviesia species. The MAT1 idiomorphs of both Knoxdaviesia species have been deposited in GenBank: K. capensis MAT1-1 (KX832965) and MAT1-2 (KX832968); K. proteae MAT1-1 (KX832967) and MAT1-2 (KX832966).

\subsection{Distribution of MAT idiomorphs in natural populations and ascomata}

The Chi-Square and two-tailed binomial tests were conducted with the null hypothesis of a 1:1 ratio of mating types. The probability of obtaining either one of the idiomorphs was therefore set as 0.5 . The P-values and 95\% confidence intervals of the tests (Table S2) indicated that almost all populations had a ratio not significantly different from 1:1 (Fig. 5) Confidence intervals were smaller in populations with large $(\geq 30)$ sample sizes. The only population that deviated from the 1:1 ratio was a small population (Franshoek; $\mathrm{n}=10$ ) of $K$. capensis sampled from $P$. repens, which is a non-preferred host of this fungus (Roets et al., 2011a). This deviation also affected the overall distribution of $K$. capensis on this host (Fig. 5). The $P$. longifolia population appears to be skewed towards MAT1-2 individuals, although this was not statistically significant. If we consider testing a single hypothesis multiple times as grounds for applying a multiple testing correction procedure, the new critical value, as defined by Bonferroni (Noble, 2009), would be $\mathrm{P}=0.003$. According to the binomial test, the Franschoek $K$. capensis population would not be significantly different from zero at this critical value, although it remains significant based on the Chi-Square test. 


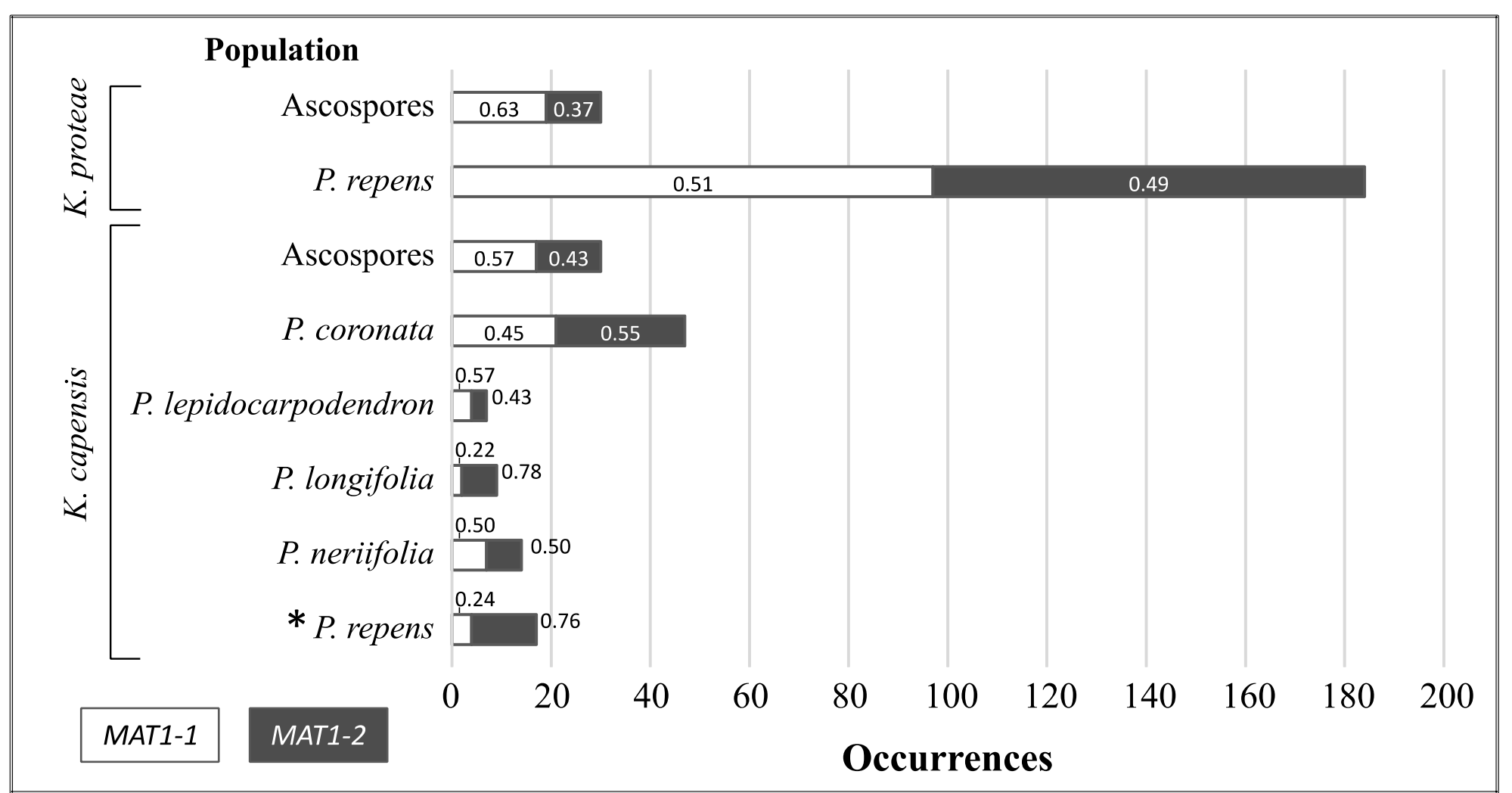

Figure 5. Distribution of the MAT1 idiomorphs in ascospore droplets and Protea populations of Knoxdaviesia capensis and K. proteae. White bars represent the number of occurrences of MATI-1 and grey the occurrences of MAT1-2. The frequency of each idiomorph is indicated on the bars. The population that showed a significant deviation $(\mathrm{P}=<0.003)$ from a 1:1 distribution is indicated with an asterisk. 

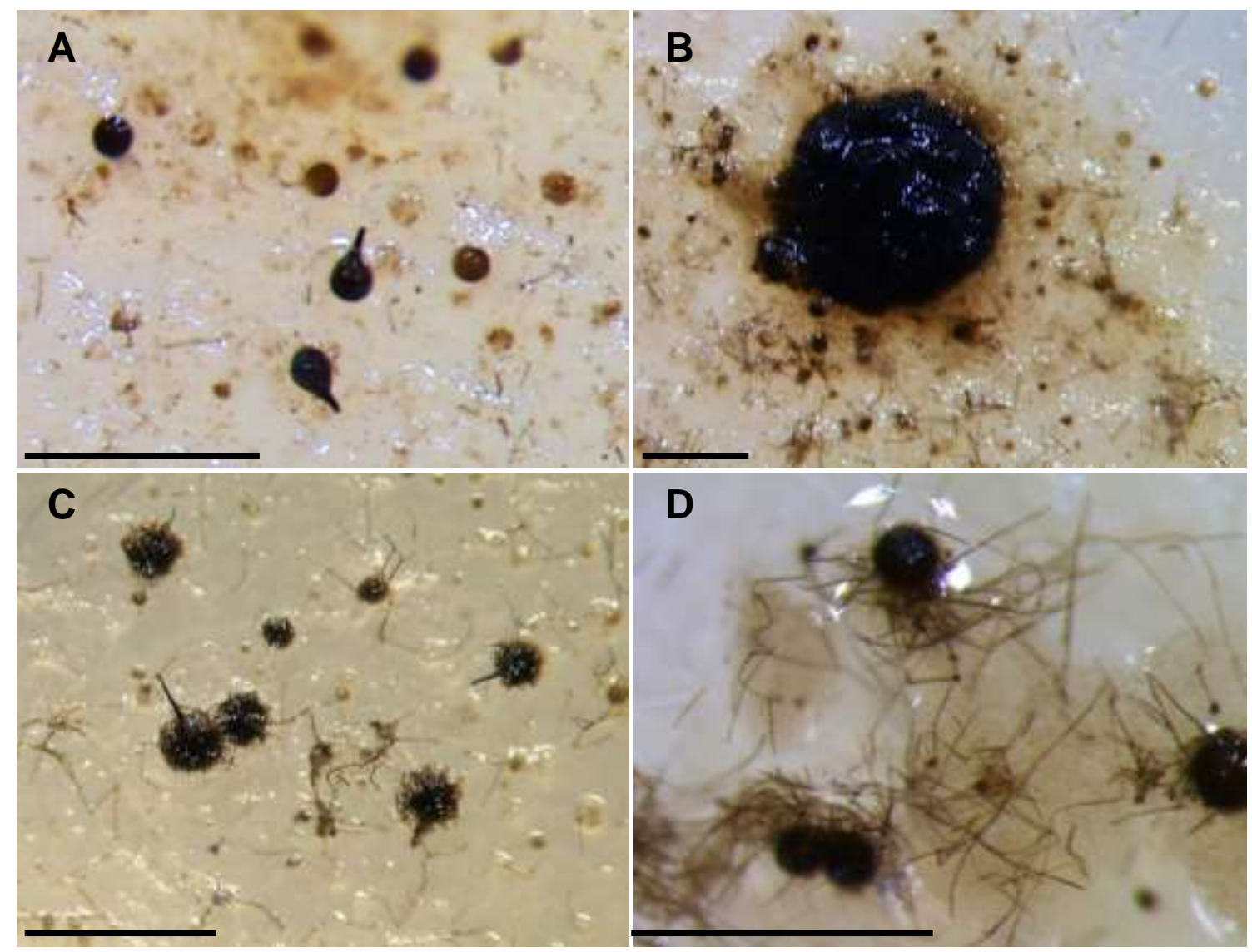

Figure 6. Mating reactions between opposite idiomorphs of Knoxdaviesia capensis and $K$. proteae in culture. A) Ascomata and developing ascomata of K. proteae (CMW408879 x CMW40883). B) Aggregations of K. capensis (CMW40886 x CBS139037) likely representing developing ascomata. C) Ascomata of $K$. capensis in a culture grown from an ascospore mass. D) Aggregations formed during an inter-specific cross between $K$. capensis and $K$. proteae. Scale bars $=0.5 \mathrm{~mm}$. 


\subsection{Knoxdaviesia mating experiments}

Only the pairing methods that involved conidial suspensions of opposite mating types showed any sign of a mating reaction. Strains sub-cultured close together did not form an interaction zone or give rise to ascomata. Ascomatal development was observed in spore mixture pairings of $K$. proteae (Fig. 6A), although ascomata were sparse and surrounded by prolific vegetative growth. Ascomata were observed in one culture of $K$. capensis grown from a droplet containing a mass of ascospores, but crosses between isolates representing opposite idiomorphs resulted only in large masses of what could have been an aggregation of developing ascomata (Fig. 6B, C). The K. capensis "aggregations" produced spore droplets containing conidia, whereas the $K$. proteae ascomata did not exude spore droplets.

Although attempts to hybridise $K$. capensis and $K$. proteae were unsuccessful, black aggregations, similar to those observed in the developing ascomata of $K$. proteae, were apparent in these interspecific crosses (Fig. 6D). It is, therefore, possible that some recognition occurs between the two species, although further ascomatal development is impeded.

\section{Discussion}

\subsection{Knoxdaviesia: outcrossing via heterothallism}

Only one MAT1 idiomorph was identified in each of the two Knoxdaviesia genomes examined, but the opposite idiomorphs could be amplified in different strains of the species. MAT1-1 and MAT1-2 individuals occur at similar proportions in the Knoxdaviesia populations from which high genetic diversity was previously detected (Aylward et al., 2014;

2015b; Aylward, unpublished), supporting the hypothesis that heterothallism underlies this 
diversity. The single $K$. capensis population that deviated from the 1:1 ratio was collected from $P$. repens, a non-preferred host (Roets et al., 2011a) on which it occurs infrequently and likely only survives until K. proteae is introduced (Aylward et al., 2015a). Furthermore, approximately half of the progeny of haploid crosses contained the MATI-1 and the other half the MAT1-2 idiomorph.

Although the production of ascomata could be induced only poorly in some intra-specific crosses, single-spore isolates of Knoxdaviesia species do not form ascomata and a mating reaction could only be induced between strains containing opposite MAT1 idiomorphs. The overall results of this study, therefore, show that both $K$. capensis and $K$. proteae have a heterothallic mating system, thereby requiring outcrossing between two individuals of opposite mating type for sexual reproduction.

Knoxdaviesia species are vectored by arthropods (Roets et al., 2011b), and possibly passerine birds, and may spend a considerable amount of time on these animals before being deposited in a suitable habitat. Since most fungi are capable of switching between sexual and asexual reproduction in response to environmental conditions (Billiard et al., 2012), the prevalence of sexual reproduction in Protea-associated Knoxdaviesia suggests that that this form of reproduction is beneficial in the Protea environment. Various trade-offs exist for sexual reproduction (Billiard et al., 2012). Disadvantages include the energy cost of developing sexual structures, the risk of failing to find a suitable mate (in the case of non-selfing species) and the possibility that locally adapted allele combinations may be broken through recombination. In Knoxdaviesia, the cost of outcrossing is likely offset by, amongst others, preventing the accumulation of harmful alleles and enabling diversification through recombination, a trait especially important for adaptation. Other than the creation of genetic diversity, production of dispersal propagules may be an essential factor underlying the prevalence of sexual reproduction in Protea infructescences. This is because ascospores are 
usually more resilient, and therefore suitable for dispersal, than their conidial counterparts (Aanen and Hoekstra, 2007).

\subsection{Evolutionary conservation between Knoxdaviesia MAT1 loci}

The homologous MATI idiomorphs of $K$. capensis and $K$. proteae were highly similar and their mating type proteins almost identical. Our interspecific mating type experiments also suggested that some determinants of recognition in strains of opposite mating type remain conserved between $K$. capensis and $K$. proteae. In contrast, the Sordariomycete MAT1-1-1 and MAT1-2-1 proteins used as a basis for comparison had low amino acid identities to each other and as well as to their Knoxdaviesia homologs (between $7.9 \%$ and $38.5 \%$ ). Studies on the mating type loci of fungi have revealed great diversity in size and gene content. Despite their conserved domains, homologous MAT1 genes in different species vary greatly and are believed to evolve more rapidly than other genes in the genome (Turgeon, 1998; Wik et al., 2008). The high level of similarity between the Protea-associated Knoxdaviesia MAT1 loci is, therefore, likely a reflection of the close phylogenetic relationship between these species (Roets et al., 2009).

Despite the recognition that may occur between $K$. capensis and $K$. proteae and the sequence similarity in their MAT1 regions, these species appear to be reproductively isolated. The initial prevention of gene flow in the common ancestor was likely facilitated by host association. Knoxdaviesia proteae occurs exclusively in P. repens (Wingfield et al., 1988), whereas $K$. capensis is found in the infructescences of nine different Protea host species (Aylward et al., 2015a; Roets et al., 2009; Wingfield and Van Wyk, 1993). The occurrence of $K$. capensis in $P$. repens infructescences was discovered only recently, this being due to the low level at which it occurs on this host (Aylward et al., 2015a). Therefore, despite the clear disparity in host range between $K$. capensis and $K$. proteae, host association does not 
completely isolate the two species, although the historical distribution of hosts may have facilitated isolation. We speculate that the Protea-associated Knoxdaviesia ancestor occupied a range of host species, but became isolated on $P$. repens. Protea repens, or at least one population of this host, may have been geographically separated from the other Protea hosts historically. Fire, a common occurrence in Fynbos vegetation in which Protea species occur (Cowling, 1992), may clear vast areas, possibly providing a mechanism for isolating host populations. Should the Knoxdaviesia ancestor have been isolated in P. repens by such means, sufficient time without gene flow would have resulted in genetic drift between the Knoxdaviesia populations on $P$. repens and the Knoxdaviesia populations on other hosts such that speciation has occurred (Slatkin, 1985; 1987).

\subsection{Knoxdaviesia MAT1 characteristics}

The most obvious difference between the MAT1 loci of the Gondwanamycetaceae and Ceratocystidaceae species is the order of genes flanking the MATl locus. Although we expected that the rearranged order in the Ceratocystidaceae might be a phenomenon common to the Microascales, the Knoxdaviesia flanking genes follow the ancestral Sordariomycete arrangement where SLA2 and APN2 flank the MAT1 locus (Debuchy and Turgeon, 2006). Since Knoxdaviesia represents the sister family of Ceratocystis and Huntiella in the Microascales (Réblová et al., 2011), we suspect that this specific rearrangement is limited to the Ceratocystidaceae and probably occurred in an early ancestor of this family.

Although the MAT1 genes in the two Knoxdaviesia species are virtually identical, the diversity of MATl genes was exemplified in the comparison with the three Ceratocystidaceae species. Differences in protein length and amino acid sequence were apparent, yet regions associated with protein function, such as the conserved domains and intron positions, remain uniform. The accessory genes (MAT1-1-2 and MAT1-2-7) in the Knoxdaviesia idiomorphs 
appeared particularly divergent in comparison to known $M A T 1$ genes, necessitating future expression analysis to determine whether they are transcribed. These could not be identified with BLAST searches, although alignments revealed similarity to Ceratocystidaceae accessory MAT1 proteins. Until recently, MAT1-1-2 genes lacked a universally conserved PFAM domain and the low complexity region in the Knoxdaviesia MAT1-1-2 gene also hampered identification. An HPYG domain is conserved in the studied Ceratocystidaceae MAT1-1-2 proteins (Wilken et al., 2014), but in Knoxdaviesia the Tyrosine (Y) residue is replaced by a Proline. As with the flanking gene arrangement, the MAT1 genes of Knoxdaviesia thus conform to the general pattern of the Sordariomycetes rather than to the derived state of the Ceratocystidaceae.

\subsection{MAT1-2-7 gene descended from MAT1-1-1}

To the best of our knowledge, the putative Knoxdaviesia MAT1-2-7 genes represent the first report of Ascomycete MAT1-2 idiomorph proteins containing an alpha domain. The presence of a truncated MAT1-1-1 gene at the same position on the MAT1-2 idiomorph is a recognised pattern in the Ophiostomatales (Comeau et al., 2015; Duong et al., 2013; Tsui et al., 2013), but this truncated MAT1-1-1 gene lacks the alpha domain. Other than the MAT1-1-1 gene, Ophiostoma quercus is also known to harbour fragments of the MAT1-1-3 gene in its MAT1-2 idiomorph (Wilken et al., 2012) and, conversely, Aspergillus fumigatus has part of the MAT12-1 gene in its MAT1-1 idiomorph (Paoletti et al., 2005). In all of these cases, the various fragments are thought to have originated from one or more unequal recombination/crossover events between the two MAT1 idiomorphs in a common heterothallic ancestor (Gioti et al., 2012). However the truncated MAT1-1-1 gene of the Ophiostomatales may be functional rather than a mere remnant of ancestral recombination. Tsui et al. (2013) showed that this 
gene is expressed in Grosmannia clavigera and suggested that the alpha domain had been lost after the crossover event.

Although the alpha domain is not readily detectable in the MAT1-2-7 gene of H. omanensis, it is nevertheless similar to its Knoxdaviesia counterpart. The intron in Knoxdaviesia MAT1-27, which lies at the identical position as the MAT1-1-1 intron, provides compelling evidence for an evolutionary link between the two genes. MAT alpha 1 domains have a DNAbinding/bending function (Gene Ontology: 0008301) and act as transcriptional activators for pheromone and receptor genes involved in the mating process (Bender and Sprague, 1987; Casselton, 2002). If the MAT1-2-7 genes of Knoxdaviesia and Huntiella had arisen from the MAT1-1-1 gene via recombination and, therefore, contained a MAT alpha 1 domain, the constraint to conserve this domain would be negated by the presence of a functional MAT1-11 protein during the mating reaction. Conversely, this domain may have mutated to prevent self-fertility, reflecting the essential benefits that outcrossing confers in these species. Expression analysis is, however, needed to verify whether the Huntiella and Knoxdaviesia MAT1-2-7 genes are functional.

\section{Conclusions}

This study is the first to investigate fungal reproduction in the Cape Floristic Region and it revealed how the Protea-associated Knoxdaviesia species maintain high levels of genetic diversity on their native hosts. Additionally, it provides information on the extent to which the MAT1 locus has diversified in the Ceratocystidaceae, a family that gave rise to many economically important pathogens. The Knoxdaviesia species considered here were shown to have a classic heterothallic MAT1 locus with strong resemblance to the ancestral gene organisation and conserved domains of Sordariomycete fungi. As such, the Knoxdaviesia 
MAT1 locus is probably a more accurate representation of the ancestral MAT1 locus of

Microascalean fungi than the MAT1 loci of Ceratocystidaceae species.

\section{Acknowledgements}

We thank the National Research Foundation (NRF) and the Department of Science and Technology (DST)-NRF Centre of Excellence in Tree Health Biotechnology (CTHB) for financial assistance. We are also grateful to two anonymous reviewers for their comments that improved the clarity of this manuscript.

\section{References}

Aanen, D., Hoekstra, R., 2007. Why sex is good: on fungi and beyond, in: Heitman, J., Kronstad, J.W., Taylor, J.W., Casselton, L.A. (Eds.), Sex in fungi: Molecular determination and evolutionary implications. ASM Press, pp. 527-534.

Alby, K., Bennett, R.J., 2011. Interspecies pheromone signaling promotes biofilm formation and same-sex mating in Candida albicans. Proceedings of the National Academy of Sciences 108, 2510-2515.

Aylward, J., Dreyer, L.L., Steenkamp, E.T., Wingfield, M.J., Roets, F., 2014. Panmixia defines the genetic diversity of a unique arthropod-dispersed fungus specific to Protea flowers. Ecology and Evolution 4, 3444-3455.

Aylward, J., Dreyer, L.L., Steenkamp, E.T., Wingfield, M.J., Roets, F., 2015a. Knoxdaviesia proteae is not the only Knoxdaviesia-symbiont of Protea repens. IMA Fungus 6, 471-476.

Aylward, J., Dreyer, L.L., Steenkamp, E.T., Wingfield, M.J., Roets, F., 2015b. Long-distance dispersal and recolonization of a fire-destroyed niche by a mite-associated fungus. Fungal Biology 119, 245-256.

Aylward, J., Steenkamp, E.T., Dreyer, L.L., Roets, F., Wingfield, B.D., Wingfield, M.J., 2016. Genome sequences of Knoxdaviesia capensis and K. proteae (Fungi: Ascomycota) from Protea trees in South Africa. Standards in Genomic Sciences 11, 1-7.

Bender, A., Sprague, G.F., 1987. MAT $\alpha 1$ protein, a yeast transcription activator, binds synergistically with a second protein to a set of cell-type-specific genes. Cell 50, 681-691.

Benson, D.A., Cavanaugh, M., Clark, K., Karsch-Mizrachi, I., Lipman, D.J., Ostell, J., Sayers, E.W., 2013. GenBank. Nucleic acids research 41, D36-D42.

Bergh, N.G., Verboom, G., Rouget, M., Cowling, R.M., 2014. Vegetation types of the Greater Cape Floristic Region, in: Allsopp, N., Colville, J.F., Verboom, G.A. (Eds.), Fynbos: Ecology, Evolution, and Conservation of a Megadiverse Region. Oxford University Press New York, pp. 26-46. 
Betley, J.N., Frith, M.C., Graber, J.H., Choo, S., Deshler, J.O., 2002. A ubiquitous and conserved signal for RNA localization in chordates. Current Biology 12, 1756-1761.

Billiard, S., López-Villavicencio, M., Hood, M., Giraud, T., 2012. Sex, outcrossing and mating types: unsolved questions in fungi and beyond. Journal of Evolutionary Biology 25, 1020-1038.

Bolger, A.M., Lohse, M., Usadel, B., 2014. Trimmomatic: a flexible trimmer for Illumina sequence data. Bioinformatics 30, 2114-2120.

Boratyn, G.M., Schaffer, A., Agarwala, R., Altschul, S.F., Lipman, D.J., Madden, T.L., 2012. Domain enhanced lookup time accelerated BLAST. Biology Direct 7, 12.

Casselton, L., 2002. Mate recognition in fungi. Heredity 88, 142-147.

Comeau, A.M., Dufour, J., Bouvet, G.F., Jacobi, V., Nigg, M., Henrissat, B., Laroche, J., Levesque, R.C., Bernier, L., 2015. Functional annotation of the Ophiostoma novo-ulmi genome: insights into the phytopathogenicity of the fungal agent of Dutch elm disease. Genome biology and evolution 7, 410-430.

Coppin, E., Debuchy, R., Arnaise, S., Picard, M., 1997. Mating types and sexual development in filamentous ascomycetes. Microbiology and Molecular Biology Reviews 61, 411-428.

Cowling, R.M., 1992. The ecology of fynbos: Nutrients, fire and diversity. Oxford University Press, Cape Town.

De Beer, Z., Duong, T., Barnes, I., Wingfield, B., Wingfield, M., 2014. Redefining Ceratocystis and allied genera. Studies in mycology 79, 187-219.

Debuchy, R., Arnaise, S., Lecellier, G., 1993. The mat- allele of Podospora anserina contains three regulatory genes required for the development of fertilized female organs. Molecular and General Genetics 241, 667-673.

Debuchy, R., Turgeon, B., 2006. Mating-type structure, evolution, and function in Euascomycetes, in: Kües, U., Fischer, R. (Eds.), The Mycota I: Growth, Differentiation and Sexuality. Springer, pp. 293-323.

Duong, T.A., De Beer, Z.W., Wingfield, B.D., Wingfield, M.J., 2013. Characterization of the mating-type genes in Leptographium procerum and Leptographium profanum. Fungal biology 117, 411-421.

Fincham, J.R.S., Day, P.R., 1963. Fungal Genetics. Blackwell Scientific Publications, Oxford.

Finn, R.D., Bateman, A., Clements, J., Coggill, P., Eberhardt, R.Y., Eddy, S.R., Heger, A., Hetherington, K., Holm, L., Mistry, J., Sonnhammer, E.L.L., Tate, J., Punta, M., 2014. Pfam: the protein families database. Nucleic Acids Research 42, D222-D230.

Gilgado, F., Gené, J., Cano, J., Guarro, J., 2010. Heterothallism in Scedosporium apiospermum and description of its teleomorph Pseudallescheria apiosperma sp. nov. Medical Mycology 48, 122-128.

Gioti, A., Mushegian, A.A., Strandberg, R., Stajich, J.E., Johannesson, H., 2012. Unidirectional evolutionary transitions in fungal mating systems and the role of transposable elements. Molecular Biology and Evolution 29, 3215-3226.

Glass, N.L., Grotelueschen, J., Metzenberg, R.L., 1990. Neurospora crassa A mating-type region. Proceedings of the National Academy of Sciences 87, 4912-4916.

Glass, N.L., Smith, M.L., 1994. Structure and function of a mating-type gene from the homothallic species Neurospora africana. Molecular and General Genetics 244, 401-409.

Harrington, T.C., McNew, D.L., 1997. Self-fertility and uni-directional mating-type switching in Ceratocystis coerulescens, a filamentous ascomycete. Curr Genet 32, 52-59.

Heitman, J., 2015. Evolution of sexual reproduction: A view from the fungal kingdom supports an evolutionary epoch with sex before sexes. Fungal biology reviews 29, 108-117. Herskowitz, I., 1989. A regulatory hierarchy for cell specialization in yeast. Nature 342, 749757. 
Hoff, K.J., Stanke, M., 2013. WebAUGUSTUS - a web service for training AUGUSTUS and predicting genes in eukaryotes. Nucleic Acids Research 41, W123-W128.

Kanematsu, S., Adachi, Y., Ito, T., 2007. Mating-type loci of heterothallic Diaporthe spp.: homologous genes are present in opposite mating-types. Curr Genet 52, 11-22.

Kronstad, J.W., Staben, C., 1997. Mating type in filamentous fungi. Annual Review of Genetics 31, 245-276.

Lehtonen, J., Jennions, M.D., Kokko, H., 2012. The many costs of sex. Trends in Ecology \& Evolution 27, 172-178.

Lin, X., Hull, C.M., Heitman, J., 2005. Sexual reproduction between partners of the same mating type in Cryptococcus neoformans. Nature 434, 1017-1021.

Lynch, M., Bürger, R., Butcher, D., Gabriel, W., 1993. The mutational meltdown in asexual populations. Journal of Heredity 84, 339-344.

Maharachchikumbura, S.S.N., Hyde, K.D., Jones, E.B.G., McKenzie, E.H.C., Huang, S.-K., Abdel-Wahab, M.A., Daranagama, D.A., Dayarathne, M., D’souza, M.J., Goonasekara, I.D., Hongsanan, S., Jayawardena, R.S., Kirk, P.M., Konta, S., Liu, J.-K., Liu, Z.-Y., Norphanphoun, C., Pang, K.-L., Perera, R.H., Senanayake, I.C., Shang, Q., Shenoy, B.D., Xiao, Y., Bahkali, A.H., Kang, J., Somrothipol, S., Suetrong, S., Wen, T., Xu, J., 2015. Towards a natural classification and backbone tree for Sordariomycetes. Fungal Diversity 72, 199-301.

Manning, J., Goldblatt, P., 2012. Plants of the Greater Cape Floristic Region. 1: The Core Cape Flora, Strelitzia 29. South African National Biodiversity Institute, Pretoria.

Marchler-Bauer, A., Derbyshire, M.K., Gonzales, N.R., Lu, S., Chitsaz, F., Geer, L.Y., Geer, R.C., He, J., Gwadz, M., Hurwitz, D.I., Lanczycki, C.J., Lu, F., Marchler, G.H., Song, J.S., Thanki, N., Wang, Z., Yamashita, R.A., Zhang, D., Zheng, C., Bryant, S.H., 2015. CDD: NCBI's conserved domain database. Nucleic Acids Res. 43, D222-D226.

Milgroom, M.G., 1996. Recombination and the multilocus structure of fungal populations. Annual Review of Phytopathology 34, 457-477.

Mitchell, A., Chang, H.-Y., Daugherty, L., Fraser, M., Hunter, S., Lopez, R., McAnulla, C., McMenamin, C., Nuka, G., Pesseat, S., Sangrador-Vegas, A., Scheremetjew, M., Rato, C., Yong, S.-Y., Bateman, A., Punta, M., Attwood, T.K., Sigrist, C.J.A., Redaschi, N., Rivoire, C., Xenarios, I., Kahn, D., Guyot, D., Bork, P., Letunic, I., Gough, J., Oates, M., Haft, D., Huang, H., Natale, D.A., Wu, C.H., Orengo, C., Sillitoe, I., Mi, H., Thomas, P.D., Finn, R.D., 2015. The InterPro protein families database: the classification resource after 15 years. Nucleic Acids Research 43, D213-D221.

Moore, D., Novak Frazer, L., 2002. Essential Fungal Genetics. Springer-Verlag, New York.

Nelson, M.A., 1996. Mating systems in ascomycetes: a romp in the sac. Trends in Genetics 12, 69-74.

Ni, M., Feretzaki, M., Sun, S., Wang, X., Heitman, J., 2011. Sex in fungi. Annual Review of Genetics 45, 405.

Ni, M., Gao, N., Kwon, N.-J., Shin, K.-S., Yu, J.-H., 2010. Regulation of Aspergillus conidiation, in: Borkovich, K., Ebbole, D. (Eds.), Cellular and Molecular Biology of Filamentous Fungi. ASM Press, Washington DC, pp. 559-576.

Nielsen, K., Heitman, J., 2007. Sex and Virulence of Human Pathogenic Fungi, in: Dunlap, J. C. (Ed.), Fungal Genomics. Academic Press, Amsterdam, pp. 143-173.

Noble, W.S., 2009. How does multiple testing correction work? Nature Biotechnology 27, $1135-1137$.

Noé, L., Kucherov, G., 2005. YASS: enhancing the sensitivity of DNA similarity search. Nucleic Acids Research 33, W540-W543.

Otto, S.P., 2009. The evolutionary enigma of sex. The American Naturalist 174, S1-S14. 
Paoletti, M., Rydholm, C., Schwier, E.U., Anderson, M.J., Szakacs, G., Lutzoni, F., Debeaupuis, J.-P., Latgé, J.-P., Denning, D.W., Dyer, P.S., 2005. Evidence for Sexuality in the Opportunistic Fungal Pathogen Aspergillus fumigatus. Current Biology 15, 1242-1248.

Perkins, D.D., 1987. Mating-type switching in filamentous ascomycetes. Genetics 115, 215.

R Core Team, 2014. R: A language and environment for statistical computing. R Foundation for Statistical Computing, Vienna, Austria. http://www.R-project.org.

Réblová, M., Gams, W., Seifert, K.A., 2011. Monilochaetes and allied genera of the Glomerellales, and a reconsideration of families in the Microascales. Studies in Mycology 68, 163-191.

Roets, F., Theron, N., Wingfield, M.J., Dreyer, L.L., 2011a. Biotic and abiotic constraints that facilitate host exclusivity of Gondwanamyces and Ophiostoma on Protea. Fungal Biology 116, 49-61.

Roets, F., Wingfield, M.J., Crous, P.W., Dreyer, L.L., 2009. Fungal radiation in the Cape Floristic Region: An analysis based on Gondwanamyces and Ophiostoma. Molecular Phylogenetics and Evolution 51, 111-119.

Roets, F., Wingfield, M.J., Wingfield, B.D., Dreyer, L.L., 2011b. Mites are the most common vectors of the fungus Gondwanamyces proteae in Protea infructescences. Fungal Biology $115,343-350$.

Seymour, F.A., Crittenden, P.D., Dyer, P.S., 2005. Sex in the extremes: lichen-forming fungi. Mycologist 19, 51-58.

Slatkin, M., 1985. Gene Flow in Natural Populations. Annual Review of Ecology and Systematics 16, 393-430.

Slatkin, M., 1987. Gene flow and the geographic structure of natural populations. Science 236, 787-792.

Staben, C., Yanofsky, C., 1990. Neurospora crassa a mating-type region. Proceedings of the National Academy of Sciences 87, 4917-4921.

Stearns, S.C., 1987. The evolution of sex and its consequences. Birkhäuser, Basel.

Tsui, C.K.-M., DiGuistini, S., Wang, Y., Feau, N., Dhillon, B., Bohlmann, J., Hamelin, R.C., 2013. Unequal recombination and evolution of the Mating-Type (MAT) loci in the pathogenic fungus Grosmannia clavigera and relatives. G3: Genes| Genomes| Genetics 3, 465-480.

Turgeon, B.G., 1998. Application of mating type gene technology to problems in fungal biology. Annual review of phytopathology 36, 115-137.

Turgeon, B.G., Yoder, O.C., 2000. Proposed Nomenclature for Mating Type Genes of Filamentous Ascomycetes. Fungal Genetics and Biology 31, 1-5.

Untergasser, A., Nijveen, H., Rao, X., Bisseling, T., Geurts, R., Leunissen, J.A.M., 2007. Primer3Plus, an enhanced web interface to Primer3. Nucleic Acids Research 35, W71-W74.

Van Wyk, M., Roux, J., Barnes, I., Wingfield, B.D., Wingfield, M.J., 2006. Molecular phylogeny of the Ceratocystis moniliformis complex and description of C. tribiliformis sp. nov. Fungal Diversity 21, 181-201.

Wik, L., Karlsson, M., Johannesson, H., 2008. The evolutionary trajectory of the mating-type (mat) genes in Neurospora relates to reproductive behavior of taxa. BMC Evolutionary Biology 8, 1.

Wilken, P.M., Steenkamp, E.T., Hall, T.A., De Beer, Z.W., Wingfield, M.J., Wingfield, B.D., 2012. Both mating types in the heterothallic fungus Ophiostoma quercus contain MAT1-1 and MAT1-2 genes. Fungal biology 116, 427-437.

Wilken, P.M., Steenkamp, E.T., Wingfield, M.J., de Beer, Z.W., Wingfield, B.D., 2014. DNA Loss at the Ceratocystis fimbriata Mating Locus Results in Self-Sterility. PloS one 9, e92180. 
Wilson, A., Godlonton, T., Van der Nest, M.A., Wilken, P.M., Wingfield, M.J., Wingfield, B.D., 2015. Unisexual reproduction in Huntiella moniliformis. Fungal Genetics and Biology $80,1-9$.

Wingfield, M.J., Van Wyk, P.S., 1993. A new species of Ophiostoma from Protea infructescences in South Africa. Mycological Research 97, 709-716.

Wingfield, M.J., Wyk, P.S.V., Marasas, W.F.O., 1988. Ceratocystiopsis proteae sp. nov., with a new anamorph genus. Mycologia 80, 23-30. 